\title{
Improving the Reliability of the Scraper-Bunker Peat Harvester
}

\author{
Alexander Yablonev ${ }^{1, *}$, Oleh Misnicow ${ }^{1}$, Alena Nekrasova $^{1}$, and Valentin Goryachev ${ }^{1}$ \\ ${ }^{1}$ Tver State Technical University (TvSTU), 170026, Afanasy Nikitin emb., 22, Tver, Russia
}

\begin{abstract}
Cases of failures of peat scraper-bunker harvesting machines are analyzed. It has been proven, that the main cause of failures is the stumpiness of the peat deposit. When interacting with the stump, there is a sharp increase in the load on all elements of the transmission of the machine, which leads to their temporary exit from the working state. The first element, that the stump encounters is the machine's elevator bucket. As a result of interaction, the bucket gets damaged in the form of ruptures, incipient and developed cracks. Proposals are formulated to increase the reliability of the scraperbunker peat harvester by installing a simple tracking device at work of the bucket elevator and improving the design of the elevator bucket itself. It is noted, that due to the initiation and development of cracks in the zone of welded seams, buckets must be subjected to flaw detection at least once a year, during pre-season maintenance.
\end{abstract}

\section{Introduction}

The extraction of milled peat, being a multistage process, is directly dependent on the reliability of the equipment, used in production [1, 2]. Operations for harvesting and transporting peat with MTF-43 machines, being the final in the cycle of milled peat extraction and cleaning it by the scraper-bunker method, largely determine the efficiency and reliability of the entire production [3], as well, as determining the quality of the final product.

Statistical models of harvester failures have been adequately described by many researchers. The laws of the distribution of the time of failure-free operation and the duration of the elimination of machine malfunctions have been determined, the availability factors of the machines have been calculated [4]. It was revealed, that the reliability of the MTF-41, 43 machines depends on the stumpiness of the deposit.

Harvester uptime statistics are classified into three groups. The first group of the sample included observations of the work of machines on a unstumpiness deposit, and the second group - on a deposit with a stump of $1-2 \%$. The third group is represented by observations of the operation of machines on deposits with a stump of the developed layer of $3 \%$. Observational data and statistical calculations are summarized in Table 1, compiled on the basis of research materials (V. G. Vasiliev and A. N. Volkov, 1979).

\footnotetext{
*Corresponding author: alvovich@mail.ru
} 
Table 1. Statistical characteristics of the reliability of scraper-bunkering machines.

\begin{tabular}{|c|c|c|c|c|c|}
\hline $\begin{array}{c}\text { Selec- } \\
\text { tion } \\
\text { group }\end{array}$ & $\begin{array}{c}\text { Mean time } \\
\text { between failures } \\
\text { (MTBF) } \boldsymbol{t}, \mathbf{h}\end{array}$ & $\begin{array}{c}\text { Mean square } \\
\text { deviation } \\
\text { from mean } \\
\text { time between } \\
\text { failures } \boldsymbol{\sigma}_{\boldsymbol{f}}\end{array}$ & $\begin{array}{c}\text { Coefficient } \\
\text { assymmetries } \\
\boldsymbol{A s}\end{array}$ & $\begin{array}{c}\text { Exscess } \\
\boldsymbol{E} \boldsymbol{x}\end{array}$ & $\begin{array}{c}\text { Availabilityf } \\
\text { actor } \boldsymbol{K} \boldsymbol{a}\end{array}$ \\
\hline 1 & 24.2 & 18.2 & 1.5 & 2.9 & 0.83 \\
\hline 2 & 19.2 & 19.7 & 1.9 & 3.6 & 0.79 \\
\hline 3 & 11.2 & 10.0 & 2.2 & 7.0 & 0.69 \\
\hline
\end{tabular}

The availability factor, which characterizes the proportion of working time during which the system performs production functions, was calculated by the authors using the formula:

$$
K_{a}=t_{f} /\left(t_{f}+t_{r}\right)
$$

where $t_{r}$ - the mean restored time of equipment, h.

By studying the reliability of technological equipment on high-moor, low-moor, transitional-moor and mixed-moor deposits with a decomposition rate of $19-21 \%$ and a stump of the developed layer of 1.0-1.6\% (A. N. Vasiliev, 2003), the parameters of empirical distributions of MTBF and recovery time were determined machines MTF-41 and MTF43A. The results of this study are summarized in Table 2.

Table 2. MTBF and recovery time of scraper-bunker machines.

\begin{tabular}{|c|c|c|c|c|c|}
\hline $\begin{array}{c}\text { Machine } \\
\text { type }\end{array}$ & $\begin{array}{c}\text { Sample } \\
\text { size, pes }\end{array}$ & $\begin{array}{c}\text { Mean time } \\
\text { developments } \\
\text { on failure } \\
\boldsymbol{t}_{\boldsymbol{f}}, \mathbf{h}\end{array}$ & $\begin{array}{c}\text { Mean square } \\
\text { deviation from } \\
\text { the mean time } \\
\mathbf{d e v e l o p m e n t s} \\
\text { for failure } \boldsymbol{\sigma}_{\boldsymbol{f}}, \mathbf{h}\end{array}$ & $\begin{array}{c}\text { Mean time } \\
\text { restored } \boldsymbol{t} \boldsymbol{r}, \\
\mathbf{h}\end{array}$ & $\begin{array}{c}\text { Mean square } \\
\text { deviation from } \\
\text { mean time } \\
\text { restored } \boldsymbol{\sigma}_{\boldsymbol{r}}, \mathbf{h}\end{array}$ \\
\hline MTF-41 & 104 & 46.7 & 42.8 & 4.8 & 5.5 \\
\hline MTF-43 & 76 & 15.9 & 12.8 & 4.2 & 2.4 \\
\hline
\end{tabular}

The likelihood of the machine being in working order on harvesting days was estimated by the author by the utilization factor $K_{u}$, the range of changes of which was $0.734 \div 0.984$ :

$$
K_{u}=\sum t_{o} / \sum x t_{d}
$$

where $t_{o}$ - the duration of the machine operation during the harvesting period of the season, $\mathrm{h} ; x$ - the duration of the harvesting interval, days; $t_{d}$ - standard daily operating time of the machine, $h$.

However, observations of the reasons for the exit from the working state of machines in the listed sources are not given. In addition, from the methodology for recording the duration of operation and downtime of equipment, it follows that failures (downtime) lasting less than 1 hour were not taken into account.

Since the transfer of a bunker harvester from a caterpillar to a pneumatic-wheel drive, characteristic of modern production, is associated with an increase in the speed of its operation $[5,6]$, it is necessary to carefully analyze the operating experience of these 
machines and the reasons for their failure, since the losses from machine downtime will be much greater.

\section{Method Used}

Field studies of the nature of downtime and fixing the time to eliminate the causes of downtime were carried out at the Orshinskoye-1 peat enterprise (production site No. 5) in the 1987 season. The sample size was represented by two sets of machines (4 units per set) MTF43 and MTF-41 with an enlarged bunker, operated on deposits with a stump of the surface layer of $S=1.5 \%$ and $S=3 \%$. From the analysis of the downtime recording time log, malfunctions not directly related to the operating conditions of the machine and being the result of a manufacturing defect, that existed on one of the machines (curvature of the front right part of the frame, which caused repeated flying off of the right track from the front guide wheel) were excluded and negatively reflected at its work. The materials were processed using standard statistical methods [7].

\section{Results and Discussion}

The lists of faults for both samples observed during the research and their statistical processing (mean time between failures $t_{f}$, mean restored time $t_{r}$, standard deviations from mean time between failures $\sigma_{f}$ and mean restored time $\left.\sigma_{r}\right)$ are given in Table $3(S=1.5 \%$ / $S=3 \%$ ). The method itself for calculating statistical characteristics is not presented due to the lack of novelty, its uniformity and versatility.

Table 3. Distribution of failures of scraper-bunker machines operating on peat deposits with a stump of $S=1.5 \% / S=3.0 \%$.

\begin{tabular}{|c|c|c|c|c|c|}
\hline Failure & $\begin{array}{l}\text { Quantity of } \\
\text { failures }\end{array}$ & $t ;, \mathbf{h}$ & $\sigma_{f}, \mathbf{h}$ & $t_{r}, \mathbf{h}$ & $\sigma_{r}, \mathbf{h}$ \\
\hline $\begin{array}{l}\text { Bucket elevator jammed by a stuck tree } \\
\text { stump }\end{array}$ & $\frac{70}{87}$ & $\frac{5.5}{4.3}$ & $\frac{2.5}{2.1}$ & $\frac{0.3}{0.3}$ & $\frac{0.22}{0.22}$ \\
\hline $\begin{array}{l}\text { Breakage of the clutch and drive for } \\
\text { engaging the unloading mechanism }\end{array}$ & $\frac{10}{8}$ & $\frac{38.2}{42.7}$ & $\frac{10.1}{11.4}$ & $\frac{0.8}{0.8}$ & $\frac{0.4}{0.4}$ \\
\hline Bucket breakage and deformation & $\frac{6}{8}$ & $\frac{50.4}{46.7}$ & $\frac{12.3}{10.2}$ & $\frac{2.2}{2.2}$ & $\frac{1.5}{1.5}$ \\
\hline $\begin{array}{l}\text { Malfunctions of the hydraulic system } \\
\text { of the drive for switching on the } \\
\text { unloading mechanism }\end{array}$ & $\frac{6}{4}$ & $\frac{51.6}{64.3}$ & $\frac{18.4}{23.1}$ & $\frac{1.0}{1.0}$ & $\frac{0.6}{0.6}$ \\
\hline $\begin{array}{c}\text { Breakage of the cardan drive of the } \\
\text { machine }\end{array}$ & $\frac{10}{11}$ & $\frac{32.1}{31.5}$ & $\frac{8.0}{8.3}$ & $\frac{1.5}{1.5}$ & $\frac{0.8}{0.8}$ \\
\hline $\begin{array}{l}\text { Broken bucket elevator drive and } \\
\text { unloading mechanism gearbox }\end{array}$ & $\frac{7}{10}$ & $\underline{56.4}$ & $\frac{23.3}{17.2}$ & $\frac{2.5}{2.5}$ & $\frac{1.7}{1.7}$ \\
\hline $\begin{array}{c}\text { Break of a chain of a drive of a bucket } \\
\text { elevator }\end{array}$ & $\frac{6}{6}$ & $\frac{50.6}{50.6}$ & $\frac{35.7}{35.7}$ & $\frac{1.8}{1.8}$ & $\frac{1.0}{1.0}$ \\
\hline $\begin{array}{l}\text { Malfunctions of the safety clutch for } \\
\text { switching on the bucket elevator }\end{array}$ & $\frac{21}{26}$ & $\frac{12.3}{10.0}$ & $\frac{4.6}{3.6}$ & $\frac{0.4}{0.4}$ & $\frac{0.3}{0.3}$ \\
\hline
\end{tabular}




\begin{tabular}{|c|c|c|c|c|c|}
\hline Breakdown of metal structures & $\underline{5}$ & $\underline{70.6}$ & $\underline{25.4}$ & $\underline{4.2}$ & $\underline{4.0}$ \\
\hline
\end{tabular}

Analysis of the above data shows the following. Such malfunctions, as jamming of the bucket elevator, breakage and deformation of buckets, open circuit of the bucket elevator and malfunctions of the safety clutch for engaging the bucket elevator can be attributed to a separate group of malfunctions, caused by a sharp increase in loads in the bucket elevator drive [8], due to stumps stuck between elevator buckets and machine metal structure in the area of the scraper. When investigating the operation of the first set of machines on deposits with a stump of $S=1.5 \%$, these malfunctions totaled $73 \%$, or 103 out of 141 malfunctions. The second set of machines, working on deposits with a stump of $S=3 \%$, was subjected to heavy loads, and this group of faults was $78 \%$ here, or 127 out of 163 faults. Thus, the largest number of malfunctions of the scraper-bunker machine of the MTF-43 type is caused by stumps, entering the scraper and jamming them between the elevator buckets and the machine's metal structure, which, without a doubt, even in a single case, can lead to significant deformation of the buckets, accompanied by the initiation and development of cracks in their body (Figure 1). On the other hand, the calculation of the mean recovery time and the mean square deviation from the mean recovery time at the level of tenths showed no difference for machines operating in deposits with a stump of 1.5 and $3 \%$.

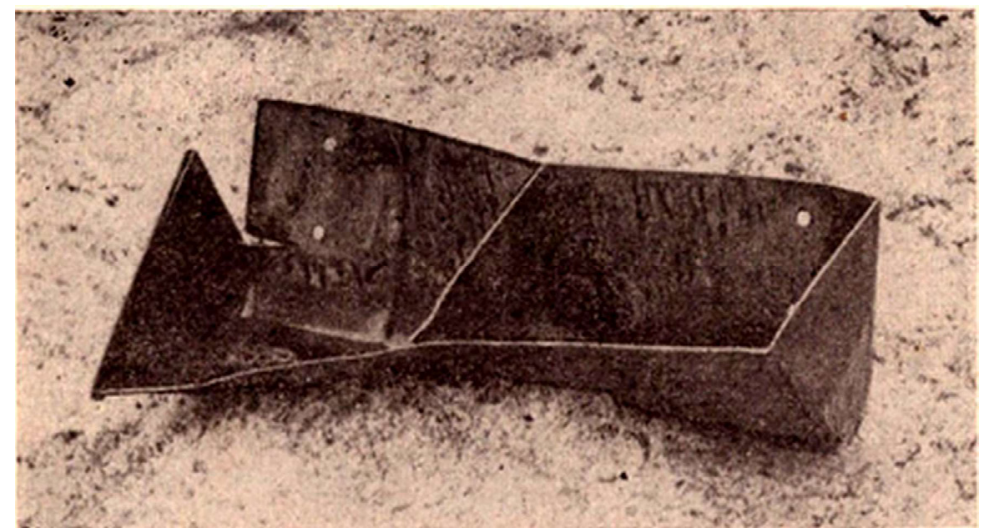

Fig. 1. Deformation of the bucket of the scraper-bunker machine with rupture and the development of cracks due to a single hit on the stump.

The specificity of the design of the machines and the peculiarities of their operation are that the operator sitting at the control panel of the tractor is not able to determine whether the bucket elevator is working, or not, since the machine's hopper covers the entire rear view, and there are no tracking devices on the machines. The operation of the bucket elevator could only be judged by the amount of peat discharged from the bunker during unloading. It is on the landed lines, that a visual inspection of the bucket elevator usually takes place with a small amount of unloaded peat, or no peat at all. If the elevator is jammed by a stump at the beginning of the roll, then the peat loss reaches $20 \mathrm{~m}^{3}$ in one pass. In this case, the time for detecting a malfunction at a vehicle speed of $2.97 \mathrm{~m} / \mathrm{s}$ is up to $200 \mathrm{~seconds}$. It was not possible to obtain more accurate data on the statistical distribution of the failure characteristics, due to the impossibility of determining the moment of jamming.

Peat not removed from the swath, when the bucket elevator is inoperative is pulled by a scraper along the map and forms losses [9]. In addition, fuel and lubricants are spent on the idle run of a tractor with a bunker machine, which increases the cost of milled peat. The 
unproductive consumption of working time for idle run of the machine, given the pronounced seasonality of production, further increases the cost of production [10].

To solve this problem, two machines MTF-43 and MTF-41 with an enlarged hopper were equipped with impellers mounted on the upper driven shaft of the bucket elevator drive (Figure 2).

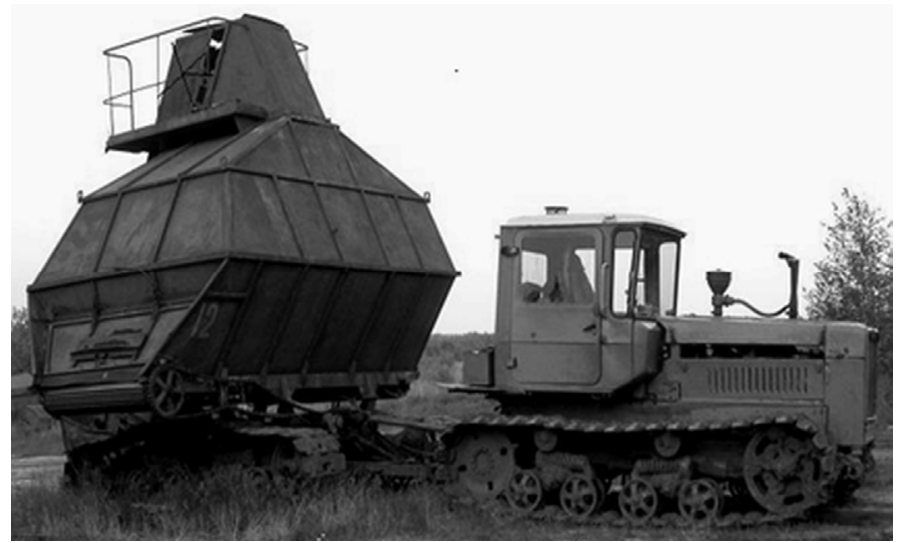

Fig. 2. A scraper-bunker machine with a bucket elevator, equipped with a tracking impeller.

During the operation of the bucket elevator, the impeller made a rotational movement and the driver of the tractor, looking back, saw this. When the bucket elevator jammed, the impeller stopped, and the driver, noticing this, had to stop, get out of the tractor cab and eliminate the malfunction. The study of the operation of machines with a control impeller showed, that the average time for detecting jamming of a bucket elevator is 18 seconds with a standard deviation from the mathematical expectation $\sigma=10$ seconds. At the same time, peat losses are on average $2.2 \mathrm{~m}^{3}$ from one jam with a standard deviation from the mathematical expectation $\sigma=1.05 \mathrm{~m}^{3}$.

However, it was required to increase the strength of the elevator buckets, which was done by the specialists of Pindstrup LLC. As the main material in the manufacture of the bucket, a corrugated flooring $4 \mathrm{~mm}$ thick made of hot-rolled steel grade St 3 was used, and along the scooping edge of the bucket, a reinforcing rib of a bent profile from the same corrugated flooring was welded (Figure 3).

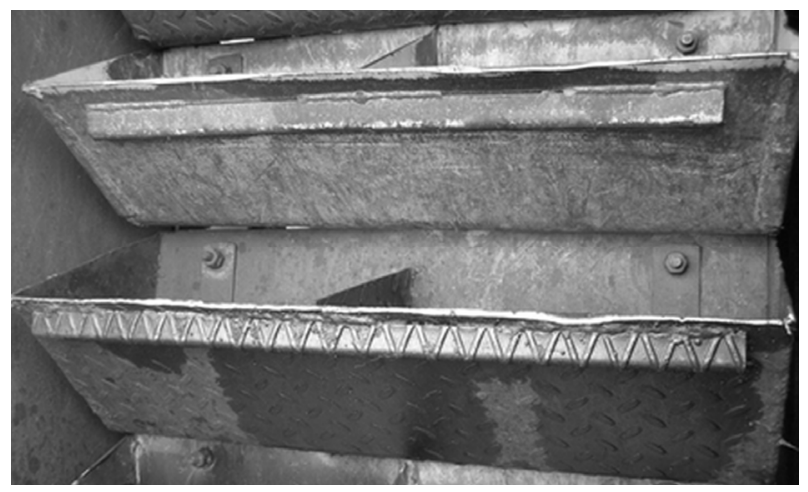

Fig. 3. Elevator buckets made of corrugated flooring at Pindstrup LLC.

Nevertheless, the analysis of the operation of the machines shows, that since cracks nevertheless arise and develop in the welded seams of the ladles, which must be repaired in 
a timely manner, the design of the ladle should be subjected to further modernization with periodic control [11], at least once a season using ultrasonic flaw.

\section{Conclusion}

As a result of the study, it was clearly illustrated, that the main reason for the inoperative state of the scraper-bunker machines is the collision of the elevator buckets with the stump, which is the more frequent, the higher the stumpiness of the deposit. It was possible to increase the reliability of the machines by installing a simple tracking device on the top sprocket of the bucket elevator. The specialists of Pindstrup LLC also contributed to the improvement of the bucket design. However, the fact of initiation and development of cracks in bucket welds requires continuation of work on strengthening bucket structures with the use of ultrasonic testing devices once a year, capable of detecting the presence of cracks in bucket welds.

\section{References}

1. V.V. Panov, O.S. Misnikov, Min. J., 7, 108-112 (2015)

2. J. Korpi, Proceed.13-th Int. Peat Cong., Tullamore, Ireland, 1, 120-122 (2008)

3. A. Yablonev, I. Gorlov, L. Kozyreva, K. Fomin, E3S Web of Conf., 41, 03001 (2018)

4. R. Lindsay, R. Birnie, IUCNUK Committee Peatland Programme, 6, 1-5 (2014)

5. J.X. Wang, C.B. Le Doux, C.B., Y.X. Li, Int. J. of Forest Engineering, 16:2, 77-85 (2005)

6. J. Y. Wong, Theory of ground vehicles (John Wiley and Sons, Ontario, 1982)

7. R. K. Pathria, Statistical mechanics (Elsevier, 2011)

8. D. Rees, Basic Engeneering Plasticity. An Introduction with Engineering and Manufacturing Applications (Butter Worth, Heinemann, 2006)

9. E. A. Kremcheev, D. A. Kremcheeva, Indian J. of Science and Technology, 9(12), 89525 (2016)

10. A. Tyurin, E3S Web. Conf., 21. 01013 (2017)

11. B. Gerike, Yu. Drozdenko, E. Kuzin, I. Ananyin, D. Kuziev, E3S Web of Conf., 41, 03011 (2018) 